\title{
The Hidden Dimension of the Energy Transition: Religion, Morality and Inclusion-A Plea for the (Secular) Sacred
}

\author{
Maarten J. Verkerk and Jan Hoogland
}

\begin{abstract}
This chapter explores the energy transition from a philosophical perspective. We argue that there is a hidden dimension in the current discussions about sustainability. This hidden dimension can be found first of all in the fact that phenomena such as the denial of global warming, the rise of populism and the increase in social contradictions are not seen in their context. At a fundamental level, it appears that all these phenomena are characterized by broken connections: man no longer feels connected with the Transcendent, the human being and the planet. On the basis of the above analysis, we outline some action perspectives. We conclude that the energy transition not only requires addressing technological, economic, social and legal problems, but that moral and religious aspects must also be discussed. Because it is precisely religious or moral values that motivate and inspire people to strive for an inclusive energy transition and release a lot of creative energy.
\end{abstract}

\section{Life-Size Dilemmas}

The issue of climate change brings enormous dilemmas. On the one hand, the reports of the IPCC provide compelling evidence that climate change is caused by human acts and that drastic measures are required to limit global warming (IPCC, 2013). On the other hand, support for climate policy is dwindling among large sections of the population, populist parties that deny the existence of climate change and/or deny that this change is caused by human acts are on the rise, and finally there is the cancellation of the Paris (2015) UNFCCC climate agreements by the United States of America. ${ }^{1}$ The sustainability issue is so great that unanimous support is

\footnotetext{
${ }^{1}$ Restored on the first day of the Biden administration.

M. J. Verkerk (凶)

Faculty of Arts and Social Sciences, Technology and Society Studies,

Maastricht University Science, Maastricht, The Netherlands

e-mail: maarten.verkerk@home.nl

J. Hoogland

University of Twente, Enschede, The Netherlands

(C) The Author(s) 2021

M. P. C. Weijnen et al. (eds.), Shaping an Inclusive Energy Transition, https://doi.org/10.1007/978-3-030-74586-8_4
} 
needed to achieve feasible solutions in the relatively short term. However, there is no consensus, either nationally or globally. The division in society is so deep that sustainability seems to become an insurmountable problem.

The philosopher Bruno Latour suggests in his book Down to Earth (2018) that the overwhelming dilemmas and the insolvability of the climate issue stem from a 'hidden dimension' in our thinking and our behaviour. He positions that hidden dimension in our scientific attitude: we have learned to place the earth at a distance and to look at it from a distance. As a consequence, we do not feel connected with the earth. This leads to indifference to the alarm systems that warn us for the climate crisis and the sirens that have been blaring full fast about global warming. Latour states that the enormous dilemmas related to our climate can only be overcome by addressing the hidden dimension in our culture: our connection with the earthly. Furthermore, he suggests that this hidden dimension has a religious character (Latour, 2017, p. 193 ff.).

Latour asserts that we can understand nothing about the politics of the last 50 years if we do not put the question of climate change and its denial 'front and centre' (Latour, 2018, p. 2). He argues that we have entered into a 'New Climatic Regime'. That means, we have arrived in a situation in which the earth changes under influence of the activities of mankind. In other words, our planet is not anymore a passive background but has become an actor that plays its role on the world stage. Latour emphasizes that the emergence of a New Climatic Regime is also evident from the increase in all kinds of social phenomena. In his view, the explosion of social inequalities and the rise of populism are symptoms from that new regime (Latour, 2018 , p. 2). He argues that the ruling classes - 'the elites' - have decided that it is pointless to act as though history were going to continue to move toward a 'common horizon', toward a world in which 'all humans could prosper equally' (Latour, 2018, p. 1).

If Latour's analysis is correct, then the climate crisis and its denial are related to (1) religious choices and (2) social inequalities. This implies that the concept and goal of an inclusive energy transition could be a very controversial one. After all, the present dialogues about the energy transition are about technology, political decisions, policy decisions, management of change, and so forth. The idea that the energy transition is also about religious choices, morality, and fighting social inequalities is highly provocative. In this chapter, we explore these provocative ideas.

This chapter has the following set-up. In Section "Latour: The Hidden Dimension" we explore the trail of the 'hidden dimension' as proposed by Bruno Latour. We argue that the hidden dimension in one way or another is related to philosophical and religious questions about the relationship between man, fellow man, and nature. In Sections "The Idea of Broken Connections" and "The Question of the Sacred" we delve into the hidden dimension on the basis of the work of philosophers Luc Ferry and Bronislaw Szerszinsky. They make it plausible that this dimension has an existential nature and can be related to the ideas of religion, worldview and the 'sacred'. In Section "The Hidden Dimension in the Worlds of Engineers, Policy Makers, and Politicians" we argue that the 'hidden dimension' comes to the fore in the values of engineers, policy makers, and politicians, in the interests of stakeholders, 
and in the ideals and basic beliefs in society. In Section "A Plea for the (Secular) Sacred" we discuss the fundamental questions about the existence of human beings in this world. It is about human connections, about what transcends people, and about renewal of human being and society. We advocate for a value system that transcends human being and/or for a (secular) sacred that unites humanity. We close with some remarks about action perspectives.

\section{Latour: The Hidden Dimension}

Latour $(2017,2018)$ wonders why climate scepticism can be rampant despite an abundance of scientific evidence. He also wonders how a ruler like Donald Trump can step out of the international climate agreement. According to Latour, Trump makes us aware that a real fight is going on in which the climate issue plays a central role. According to Latour $(2018$, p. 5), there are two options. The first is to deny that something is going on and fight for survival of the members of your own clan, if necessary, at the expense of the rest. The second is to change course radically and to revise fundamentally the relationship of human being to the planet. For Latour, denial is not an option, so he chooses to face the challenge. That option, however, imposes challenging demands on those involved and in particular on those who are scientifically engaged with the climate issue and who have a great deal of insight into it.

Since enlightenment, we have always assumed that humanity could succeed in increasing its knowledge of the world and could use it to steer development towards prosperity, happiness and well-being. In an increasingly rational organization of the world, local interests would increasingly give way to a global order in which the public interest would be leading. Latour argues that the climate problem clearly shows that this line of thinking is too simple. After all, the natural world can no longer handle humanity's growing claims and 'strikes back'. He expressively describes the change in the relationship between man and nature by using the metaphor of a stage and its actors. He writes: "Humans have always modified their environment, of course, but the term designated only their surroundings, that which, precisely, encircled them. They remained the central figures, only modifying the decor of their dramas around the edges. Today, the decor, the wings, the background, the whole building have come on stage and are competing with the actors for the principal role. This changes all the scripts, suggests other endings. Humans are no longer the only actors, even though they still see themselves entrusted with a role that is much too important for them" (Latour, 2018, p. 43). In other words, nature is no longer the objectively recognizable, technically accessible and economically available environment in which people shape their own life and culture, but has itself become a player. This is evidenced by the changes in our environment: global warming, the melting of glaciers and ice caps, rising sea levels, an increasing frequency of extreme weather events with devastating consequences, and the depletion of natural resources. 
How did it get so far that nature strikes back? That nature has become a political actor? Latour (2018, pp. 64-72) blames modern science for paving the path to the New Climatic Regime. Science has developed a 'Global' approach: in the way it pursued the quest for knowledge it put nature at a distance and neglected the interactions between mankind and its natural environment. Scientists are trained as objective and rational observers who are 'external to the social world' and 'indifferent to human concerns'. Precisely this external and indifferent approach nourishes the climate scepticism of action groups like the 'yellow jackets': people with little influence on the climate problem, who are nevertheless the victims of the explosion of inequalities and have to bear the burden of the climate problem. According to Latour, we will have to look at nature in a different way. Namely, no longer as a passive body that allows rational manipulations by people, but as part of a complex whole that plays an active role in the creation of sustainability - which depends on a range of critical balances interacting through various mechanisms in the whole of a complex adaptive system. In his book Facing Gaia (2017), Latour calls this complex whole 'Gaia', and in his more recent book Down to Earth (2018) he speaks of the 'terrestrial'. Latour believes that the way scientists deal with the planet requires a new mindset. Especially, the mentality that nature is 'sensitive to human actions' (Latour, 2018, p. 67).

More generally, Latour (2017, pp. 206-208) reproaches modern man for his belief that the Apocalypse has already taken place and that the 'Promised land of Modernity' has already been reached. He contends that modern man hears the alarm systems about the climate crisis. He argues that modern man, deep down, does not acknowledge the climate crisis and does not believe that a change in his way of life is inevitable. Therefore, Latour believes that the origin of climate scepticism lies not in a lack of solidity of our knowledge and understanding of nature but stems from our own existential position in nature. We cannot accept that the 'Promised Land of Modernity' has not arrived. We cannot accept that nature strikes back and that the whole scene has changed.

If we let the previous thoughts sink in, the contours of the 'hidden dimension' of the climate crisis become increasingly clear. The first contour is found in the interpretation of the relationship of man with his fellow human beings and the relationship of man with nature. These relationships are characterized by terms such as 'external', 'indifference', and 'detachment'. The second contour is found in the existential interpretation of humanity. In this interpretation, terms like 'religious origin', 'Promised Land', 'Apocalypse', and 'Gaia' come to the fore.

\section{The Idea of Broken Connections}

How to understand the changing relationship of man with fellow man and man with nature? To answer this question, we have to dig deeper in the history of western philosophy. Luc Ferry's book Learning to Live. A User's Manual (2010) is used as a guide here. Ferry believes that we need philosophy to 'understand the world we live in' and to 'live a better and freer life'. He shows that in the course of history different 


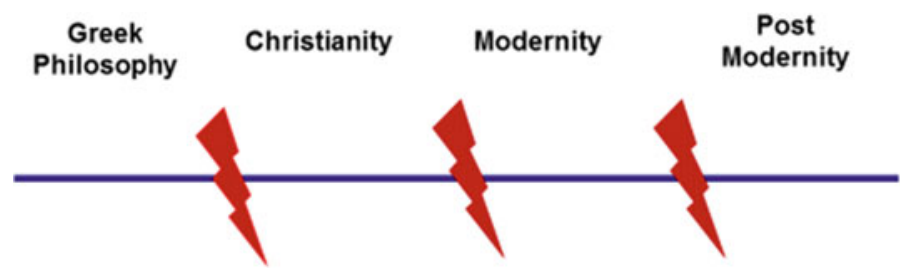

Fig. 1 Different connections of man with fellow men and nature

philosophies or 'manuals' have been provided to learn to live, as will be discussed below. Ferry's objective is to make the starting points of these manuals explicit and to describe the challenges for today.

Ferry tries to understand the history of our culture by asking three questions:

(1) How to understand reality?

(2) How to live?

(3) How to find salvation?

The first question is related to the (perceived) order in our reality, the second question to morality, and the last question to wisdom and the meaning of life. The questions of Ferry are related to the main questions of the well-known philosopher Immanuel Kant: 'What can I know?' 'What should I do?' and 'What can I hope?'

Ferry runs through the history of philosophy with big steps. He distinguishes four main traditions: Greek philosophy, Christian philosophy, modern philosophy, and post-modern philosophy, see Fig. 1. He tries to understand every tradition from within by using the three previously asked questions as signposts. Ferry asks himself whether the history of philosophy can be interpreted as a history of continuity or has to be understood as a history of discontinuity. Let us first follow the road marked by Ferry.

Ferry discusses the Greek philosophy on the basis of the thinking of the Stoics. The Stoics describe the cosmos as a living organism or a giant creature. Every organ fulfils a beautiful function and cooperates harmoniously with the other organs. The Stoics believe that the order of reality is a 'divine order.' The order of the universe is also rational, consonant with what the Greeks called 'Logos'. The Stoics furthermore believe that the cosmos is not only harmonious but also just and good. As a consequence, the answer to the question 'How to live?' is that every person has to live in agreement with the divine order of society. Every human being has to take his or her own position in society. That means, the hierarchical relationships of masters and slaves, males and females, and Greeks and barbarians have to be respected. In Stoic thinking, death does not mean a definitive end, but is a transition to another state. Here we find an answer to the last question about salvation: man will be united with the cosmic order.

Ferry shows that the rise of Christianity implies a radical break with Greek thinking. Firstly, this break is evident in the different understanding of the order of reality. The Stoics believed that the Logos, the divine principle, was identical to 
the harmonious order of the world. Christians, however, identified the Logos with a unique person: Jesus Christ, the Logos incarnate. This break expressed itself also in morality: the natural order as the basis for ethics is replaced by 'the law of love'. Finally, Christians believe that salvation does not imply a unification with the cosmic order but involves redemption and resurrection in a new body.

Ferry indicates that the emergence of modern philosophy involves a radical break with Christian thinking. Modern man becomes the foundation for understanding the order of the world, developing morality and realizing salvation. The idea of discovering the divine order is substituted by creating or constructing order as human beings. The law of love is replaced by a ratio-based ethics. Finally, any belief in a divine redemption is rejected in favour of salvation in the way of science and technology. Consequently, the idea of eternal life is rejected and it is believed that life ends with death.

The era of postmodern thinking has been ushered in by the philosopher Friedrich Nietzsche. Ferry demonstrates that there is a radical break between modern and postmodern thinking. Nietzsche believes that reality is not an ordered or harmonious unity, but an infinite multitude of forces and impulses that constantly collide. He believes that a universal ethics does not exist. Every individual human being has to develop his own values and his own 'grand lifestyle'. Finally, he thinks that our salvation lies in a life worth living, in an intense, exalted and courageous life. A life in which there is no room for regret and repentance.

What do we learn from the philosophical considerations of Luc Ferry? Our first conclusion is that every philosophical era is characterized by different beliefs about the order of reality, human relationships, and the meaning of life. The context in which we interpret our observations of society and nature is not a constant, and different belief systems make us draw different conclusions and take different actions. That also implies that, in doing scientific research and developing technological solutions for the energy transition we cannot ignore our beliefs about reality, fellow man, and the meaning of life. We have to make these beliefs explicit. Our second conclusion is that the course of western history can be described as a history of broken connections. The rise of modern thinking implied the breaking of the relationship of man with God. Additionally, the inherent and interdependent relationship of man and nature was broken and replaced by an instrumental one in which man exploits nature. The rise of postmodernity implied the breaking of the relationship of man with fellow man and perfected the break of human being and nature.

Latour states that modern man is disconnected from nature and fellow man. He also argues that these disconnections have a religious origin. Ferry gives relief to these observations. He showed that man was originally connected to the Logos or God, fellow man and nature (Greek thinking, Christian thinking). In the course of history, however, these connections have been broken (modern thinking, postmodern thinking). The breaking of these connections can be interpreted as an existential or religious act. As a result, restoring these connections also requires an existential or religious act. 


\section{The Question of the Sacred}

Bronislaw Szerszynski also addresses the connections of man and nature. He describes these connections in terms of 'sacred' and 'secular'. At first sight, it seems to be farfetched to relate issues of the energy transition with words like 'sacred' and 'secular'. However, in the course of this section we will discover how important these concepts are.

Szerszynski wonders in his book Nature, Technology and the Sacred (2005), how we have to judge our time. He argues that Max Weber's vision of the 'disenchantment of the world' is widespread. Under the influence of science and technology we have stripped nature from mysterious powers and divine interventions. We no longer believe in gods, demons and spirits who can help, hinder or frighten us. We believe today that reality can be understood in mathematical terms and physical laws. In fact, we can control nature through science, realize its potential through technology, and determine its value in the market. In summary, 'disenchantment' means that 'religion has been replaced by science and technology' (Szerszynski, 2005, p. 14).

Szerszynski notes that present thinking is characterized by an asymmetrical vision of the sacred and the secular. The secular is seen as self-evident, as something that needs no explanation. But the sacred is interpreted as something aberrant, as something so special that it requires further explanation. It is precisely because of this asymmetry that he wants to 'problematize' the secular.

Szerszynski shows that the story of the concepts of the sacred and the secular is much more complex than described in many popular and philosophical reflections. In the classical world the term 'secular' or 'profane' has always been interpreted religiously. He refers to the original meaning of the word 'profane': pro-fanum is the space in front of the sanctuary. In other words, in classical thinking, the profane was always a space within a sacred cosmos. Modern thinking, however, states that the world is completely profane and has no spiritual meaning whatsoever. In this way of thinking the secular presents itself as a self-grounding, independent reality. Szerszynski wants to problematize this vision of reality. He believes that modern thinking has not disenchanted the world, but has replaced one belief by another. He even wonders if we should not see the story of the disenchantment of nature as the 'creation myth of modern society' (Szerszynski, 2005, p. 7). Szerszynski argues that modernity - and therefore modern views of the sacred and the secular - must be seen as a specific product of our religious and cultural history. He even calls the secular a religious phenomenon. In his view, the sacral in modern times has not disappeared. Rather, it has been ordered or organized in a different way.

Szerszynski uses the word 'sacred' in a general sense. He writes: "I am using 'sacred' in a more general sense, to understand the ways in which a range of religious frames are involved in our ideas of and dealings with nature and technology (...) it is the ground against which particular historical phenomena or ideas appear as intelligible figures" (Szerszynski, 2005, p. ix). He refers to the views of Kay Milton who defines the sacred as 'what matters most to people' and to the definition of Paul Tillich who describes religion as ‘ultimate concern' (Szerszynski, 2005, p. ix). 


\section{Reordering of the sacred}

Christian thinking

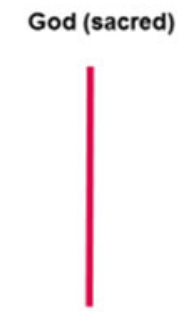

Modern thinking

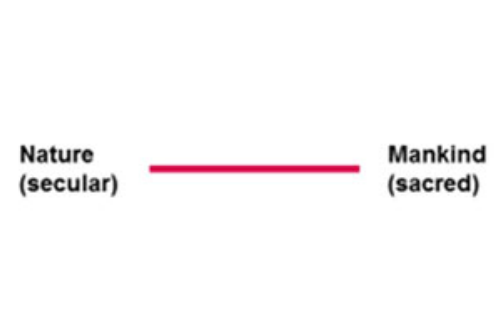

Postmodern thinking

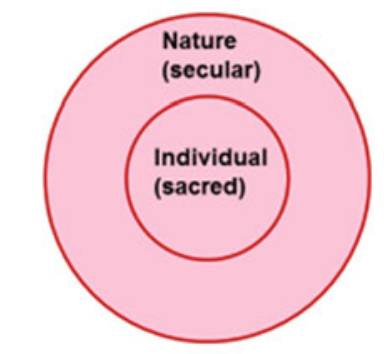

Nature, human

being (secular)

Fig. 2 The reordering of the sacred in the course of history

Szerszynski describes the development of the sacred under the heading 'The Long Arc of Transcendental Religion.' The story begins with the primal sacred of indigenous peoples who experience reality as a unity of the natural and the divine. They make no distinction between the empirical and the transcendent, the secular and the sacral. The story ends with the plurality of the postmodern sacred in which the unity of the natural and the divine has collapsed. The result is the emergence of a multiplex reality that is founded in the subjective experience of the individual.

We would like to highlight three stages in 'The Long Arc', see Fig. 2.

In the Protestant sacred the gap between the transcendent divine and the secular is seen as infinitely large and infinitely small, as absolute and disappearing into nothingness. ${ }^{2}$ On the one hand, the Transcendent is depicted as the Exalted, the Almighty. On the other hand, $\mathrm{He}$ is near and directly accessible to the individual, without heavenly or earthly intermediary. The Protestant sacred opens the way for the individual — created in the image of God — to serve God in all areas of profane life. Szerszynski uses the word 'profane' almost in its original meaning here: the 'profane' is directly related to the sacred and acquires meaning from the sacred.

In the modern sacred, which encompasses Enlightenment and Romanticism, the vertical transcendent axis is increasingly being drawn into the empirical world. In the Protestant sacred, 'being' and 'order' in nature are related to a 'supernatural origin,' but in the modern sacred they are increasingly seen as properties of reality itself. The world is becoming profane in a new sense, namely, as a space that is only profane

\footnotetext{
${ }^{2}$ In Szerszynski's 'The Long Arc of Transcendental Religion' the Protestant sacred is preceded by the 'monotheistic sacred' of the historic religions, including the world religions of Judaism, Buddhism, Christianity and Islam. In his view, the monotheist sacred is characterized by a dualist distinction between this world and a transcendental reality. Given the line of thought we develop in this chapter, it is not necessary to discuss the monotheistic sacred.
} 
and has no relationship with the sacred. The profane has become 'total' or 'absolute' This development, however, does not lead to the disappearance of the sacred but to a reordering of the sacred: the sacrality of the human subject. In other words, man assigns a divine character to himself. The reordering of the sacred also leads to a new vision of salvation. Christ's redemption is replaced by self-redemption. In the tradition of Enlightenment, emphasis is placed on the path of science and technology and in the tradition of Romanticism on authenticity and solidarity with the world.

In the postmodern sacred, the Protestant sacred has collapsed entirely. A multiplex reality arises that is filled with and constituted by different views on man and reality that are founded on subjective experience. People no longer focus on a natural or divine order. In fact, they reject such an order that gives direction to their lives. Instead, they develop their own philosophy of life based on 'what feels right' and shape their 'own religion'. The idea of a common vision of man and reality, which was still present in the modern sacred, has given way to a plurality of visions.

What can we learn from Szerszynski's fascinating sketch of the history of the sacred and the secular? First, Szerszynski poses probing questions about our relationship with the earthly. In view of the climate crisis and the energy transition these questions are of an existential nature. These are questions like: What is still sacred for us? Or: What transcends our personal interests? Or: What may it cost us? Second, we conclude that Szerzynski-if his analysis is correct-sketches a gloomy picture. The sacred is concentrated in the individual. Every individual develops his or her own philosophy of life. In other words, there is no sacred that transcends the individual. If this is indeed the case, then our starting point for tackling overwhelming issues like the energy transition is not very favourable.

\section{The Hidden Dimension in the Worlds of Engineers, Policy Makers, and Politicians}

The message of Latour is that the hidden dimension is also present in the worlds of engineers, policy makers, and politicians. The philosophers Ferry and Szerszynski confirm this analysis in their ideas of broken connections and the absence of a shared meaning of the sacred. In this section we will investigate the question 'how' the hidden dimension is present in and penetrates the practices of engineers, policy makers, and politicians. We focus on these practices because they largely determine how humanity interacts with nature.

\section{Practice Approaches}

It goes without saying that the hidden dimension of the worlds of engineers, policy makers, and politicians cannot be investigated by scientific approaches that are 
based on objectivity, rationality, and progress. The main reason is that the scientific approach, according to Latour, in its core values denies the existence of this hidden dimension. Nicolini (2012) proposes that scientists have to change their research methods to understand what really happens in the worlds of engineers, policy makers, and politicians. In his view, scientists must not focus on positive facts and rational data, but on meanings, decisions and actions. De Vries and Jochemsen (2019) argue that these worlds have a normative character and are co-shaped by philosophical and religious ideas. The approaches advocated by Nicolini (2012) and De Vries and Jochemsen (2019) are called 'practice approaches' because they try to understand what really happens in the worlds of engineers, policy makers, and politicians. Moreover, they refer to 'social practices' to emphasize the social dimension of practice approaches in the worlds of engineers, policy makers, and politicians.

Practice approaches are fascinating as they deal with real world complexity and render insight into how practitioners perceive this complexity:

- Complexity. Practice approaches offer tools to characterize, analyse and understand the complexity of social practices.

- Practice-centred. Practice approaches take their starting point in social practices. They take the world of the engineer, policy maker, and politician seriously. They try to understand what drives them to excel and what values they strive to anchor in their work.

- Bodies and technology. Practice approaches bring to the fore that in all practices bodily activities and material things play a critical role. Human practices without body and technology do not exist.

- Stakeholders. Practice approaches recognize that social practices act in a complex world. In other words, every social practice has stakeholders that have an interest in the goings-on within a practice.

- Spirit of the times. Practice approaches are aware that there is something like 'spirits of the times'. The idea of the 'spirit of the time' is difficult to grasp. Despite that, practice approaches try to address this topic.

- Human phenomena. Practice approaches leave space for human phenomena like initiative, creativity, conflict, power, deceit, and so on. Practice approaches show that these types of phenomenon are relevant and co-determine the performance of practices.

In this chapter, we introduce the triple-I framework as a simple framework to help us understand the social practices of engineers, policy makers, and politicians. This practice framework was developed in close collaboration with engineers and managers, and provides us with a handle to explore where the hidden dimension is expressed in the social practices of engineers, policy makers and politicians. 


\section{Triple I Framework: Three Perspectives}

The Triple I framework offers three different perspectives to investigate social practices (Verkerk, 2014, 2019). We would like to emphasize the word 'perspective'. The three 'I-s' do not stand for three different 'parts' of a practice but present three different points of view to understand social practices and the hidden dimension therein. Each one of the three perspectives reveals specific characteristics. Combining the perspectives results in a richer understanding of social practices. We distinguish the following perspectives:

(1) The first perspective is 'identity and intrinsic values'. This perspective focusses on the opinions and beliefs of the main actors in a social practice about their own role and identity and about the main values to be embedded in their work.

(2) The second perspective is 'interests of stakeholders'. This perspective highlights the interests of third parties (stakeholders) that have a stake in a social practice. It also underlines the mechanism by which these stakeholders exert influence on that practice.

(3) The third perspective is 'ideals and basic beliefs'. This perspective puts the spot light on the influence of ideals and basic beliefs in society on a social practice. It investigates how social practices are co-shaped by societal norms and values.

This framework is helpful to gain an understanding of the practice of engineers, the practice of policy makers, and the practice of politicians, see Fig. 3. Through a Triple I analysis of each of these practices a picture emerges of the similarities, differences, and complementarities of the three practices.

\section{Identity and Intrinsic Values}

The first I highlights the 'identity and intrinsic values' of a practice. It has to be noted that 'identity' and 'intrinsic values' are closely related. They can be described as two sides of a coin. On the one hand, the identity of a practice is specified in more detail by the intrinsic values. After all, it specifies which values are important in the practice concerned. On the other hand, the intrinsic values co-shape the identity of a practice. It goes without saying that the identities of the practices of engineers, policy makers, and politicians are quite different. The practice of engineers is about making technology work for society, the practice of policy makers is about designing effective and efficient policy interventions for the good of society (in health care, education, culture, industry, and so on), and the practice of politicians is about defining the 'good of society', i.e. solving or tackling value dilemmas, with respect for democratic legitimacy, and overseeing public administration for the manner in which it upholds societal values (fairness, equity, justice, transparency and so forth). Each of these practices have their own intrinsic values. For example, for engineers the values of creativity and innovation score high and for politicians the values of support and 

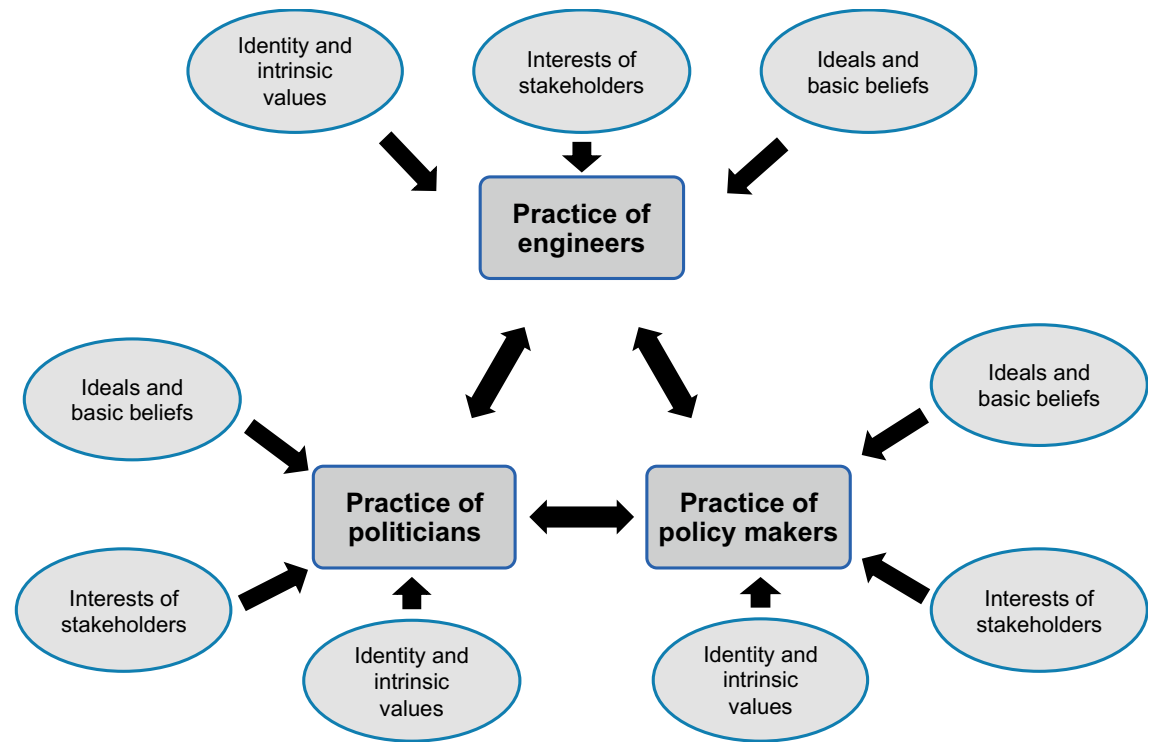

Fig. 3 The Triple-I framework for a engineering practices, $\mathbf{b}$ policy making practices, $\mathbf{c}$ and political practices. These practices can be understood from the perspectives 'identity and intrinsic values', 'interests of stakeholders', and 'ideals and basic beliefs'

feasibility. The Triple I framework suggests that hidden dimensions are present in the intrinsic values of each of these practices. The use of this framework invites engineers, policy makers and politicians to reflect on their intrinsic values and to wonder to what extent they express the connection between man and fellow man, and man and nature.

\section{Interests of Stakeholders}

The second I highlights the complex environments in which engineers, policy makers, and politicians operate. They are embedded in different social networks with many other actors and stakeholders. In other words, every practice has its own configuration of stakeholders. Among practices, these configurations may partly overlap. For example, engineers are mainly concerned with users, policymakers with citizens, and politicians with voters. Each stakeholder has an interest in influencing these practices to reach an outcome benefiting the relevant stakeholder. The Triple I framework suggests that hidden dimensions are present in the influence of the stakeholder configurations of each practice, and it invites engineers, policy makers and politicians to reflect on the influences of stakeholders on their practices. What types of values do they promote? Vales of 'externality', 'indifference', and 'detachment'? Or values of 'close proximity', 'involvement' and 'connectedness'? We do acknowledge that every stakeholder has its own justified interests. However, to what extent 
are their justified interests embedded in modern views on man, organization, and market that promote broken relationships?

\section{Ideals and Basic Beliefs}

The third I reveals the (hidden) ideals and basic beliefs in society. As said before, the practices of engineers, policy makers, and politicians cannot be seen as isolated from society at large. They are embedded in society as a whole, as all practitioners engaged in the different practices are also engaged in other social contexts, such as marriage, family, sports, leisure, church, and so on. In all these other social contexts, practitioners breathe in the ideals and basic beliefs of society, like the air they breathe, without realizing it. The framework suggests that the ideals and basic beliefs of the modern/postmodern society co-shape the hidden dimensions, as stipulated by Ferry and Szerzynski.

\section{Feelings of Unease}

Many engineers, policy makers, and politicians will argue that they act in an objective and rational way and that hidden dimensions do not pertain to their practice. They will also argue that stakeholders only have an 'objective' and 'rational' influence on their practice and that, in their work as practitioners, they are immune for ideals and basic beliefs in society. A recognition of hidden dimensions is certainly at odds with what practitioners perceive as good engineering practices and good policy making practices. Most practitioners have not been trained to be sensitive to hidden dimensions, nor to explicitly account for the influence of their world view, ideals and basic beliefs in their work. This is why we need to acquire a better understanding of how social practices are shaped and pervaded by hidden dimensions.

\section{A Plea for the (Secular) Sacred}

We would like to start with a short recap of our line of thought. The philosopher Bruno Latour suggests that the overwhelming dilemmas and the insolvability of the climate issue has to do with a 'hidden dimension' in our thinking. The first contour of this hidden dimension is related to the broken connections of man on the one hand and fellow man and nature on the other hand. The second contour is found in questions pertaining to the meaning of life that have a religious or philosophical background.

The philosopher Ferry sheds light on the idea of broken dimensions. He argues that broken connections do not just show up in our society but are the result of a long evolutionary process unfolding throughout the history of humankind. He 
shows that in this historical process society developed new ideas and beliefs about the meaning of life. These ideas and beliefs pervade society and social practices, without explicit recognition of their role in social practices. That is why they are referred to as a 'hidden dimension'. The philosopher Szerszynski approaches the 'hidden dimension' from the perspective of sacrality. In our postmodern society, he argues, every individual defines what is sacred to him or her in relationship to fellow man and nature. That means, there are no shared values in postmodern society to help us collectively address the climate issue.

The key question of Latour is: Is a radical revision of our relationship with the earthly possible? And what would be the contours of such a revision? Ferry rejects the idea that the present postmodern beliefs can be a source for a radical revision of the relationship of man with fellow man and nature. He defends a rehabilitation of the concept of transcendence (Ferry, 2010, pp. 232-239). The concept of transcendence implies that there is something that is greater that man, something that surpasses every individual and individual interests. He argues that values such as 'truth', 'beauty', 'justice' and 'love' do no originate from individuals but stem from how we experience and interact with others, in relationships between individuals and in social communities. The idea of transcendent values is very helpful to promote a radical revision of our relationship with the earth. Szerszynski also believes that the postmodern sense of the meaning of life prohibits us to tackle the challenges of our global society. He argues for a concept of sacrality in which plurality and unity are connected to each other. He searches for an idea of a transcendent axis that makes a plurality of perspectives on reality possible (Szerszynski, 2005, pp. 170, 175).

The philosophers Ferry and Szerszynski show us a way for man and fellow man, for man and nature to be reconnected. It is about values that rise above us. It is about the recognition that man is neither the origin of values, nor the creator of connectedness, nor the source of meaning, and nor the source of sacrality. On the contrary, it suggests that being human has to do with the art of receiving: receiving values, receiving connections, receiving meaning, and receiving sacrality. The idea of receiving presupposes that there is 'somebody' or 'Somebody' who offers values, connections, meaning, and sacrality.

What we can learn from the philosophers is that every practitioner, whether engineering professional, policy maker or politician, has a responsibility towards society and the planet to reflect on values, connections, meaning and sacrality. Inevitably, in a hyper-individualistic society like ours, practitioners' reflections on these deep questions will yield a large diversity of answers. The hard question then is: is there a common sacred or are there common values that connect man with fellow man and man with nature? We would like to point out that there are many national and international initiatives that transcend the plurality that characterizes our society. With regard to the international initiatives, we would like to draw attention to the Sustainable Development Goals as developed by the UN and the Paris (2015) UNFCCC climate agreements, which have again been signed by the United States of America. We would like to suggest three possible common values or forms of sacrality. The first one is the value or sacrality of the earth: mankind has no choice but to act in accordance with the rules of the earthly ecosystem; rules we learn through trial and 
error. The second one is the idea of the dignity of human beings: every human being has the right to live in a healthy and sustainable world. The third one is the idea that we should leave a good earth to our children and grandchildren. These three different values or sacralities do not exclude each other. Each of them recognizes the idea of receiving, the idea of something that transcends the individual, and the idea that there is something sacred that man should not enter or tarnish. Finally, each of them offers action perspectives.

\section{Action Perspectives}

In this chapter we have investigated the energy transition from a philosophical point of view, in the context of the climate change debate. Bruno Latour claims that the climate crisis has a 'hidden dimension'. He argued that the first contour of this dimension is found in the interpretation of the relationship of man with fellow man and the relationship of man with nature. In the course of history these connections have been broken. The second contour is found in the existential interpretation of man. It is about the idea that our ultimate beliefs about values, connections, meaning, and sacrality have a religious or philosophical origin. We have claimed that the relationship of man with fellow man and man and nature only can be reinstated by the recognition of values that transcend human being as an individual and/or the recognition of a (secular) sacred.

In our view, the Triple I framework helps us to identify potential action perspectives with respect to revealing the hidden dimension in the social practices of engineers, policy makers, and politicians. The first I (identity and intrinsic values) invites engineers, policy makers and politicians to address the identity and the hidden values in their own practices. In the context of the energy transition, the key question here is: do these values lead to a further increase in inequalities in society or to the notion that we have to restore broken relationships within society and between society and nature? The second I invites engineers, policy makers and politicians to engage in dialogue with stakeholders. These dialogues can contribute to a common understanding that there is no plan B for the planet. The third I invites practitioners to reflect on their religious values or their philosophical choices with respect to fellow man and our ecosystem.

We do not believe that technology 'as such' will solve the problems of the energy transition. We need religious, philosophical, and existential discussions about the human condition in times of climate crisis. Only through such discussions may we feel motivated, inspired and possibly morally obliged to realize the energy transition in an inclusive manner and unleash the creativity required to make this transition possible. 


\section{References}

de Vries, M., \& Jochemsen, H. (Eds.). (2019). The normative nature of social practices and ethics in professional environments. IGI Global.

Ferry, L. (2010). Learning to live: A user's manual. Canongate.

IPCC. (2013). Climate change 2013: The physical science basis.

Latour, B. (2017). Facing Gaia: Eight lectures on the new climatic regime. Polity Press.

Latour, B. (2018). Down to earth: politics in the new climatic regime. Polity Press.

Nicolini, D. (2012). Practice theory, work, and organization: An introduction. Oxford University Press

Szerszynski, B. (2005). Nature, technology and the sacred. Blackwell.

Verkerk, M. J. (2014). A philosophy-based "toolbox" for designing technology: The conceptual power of Dooyeweerdian philosophy. Koers-Bulletin for Christian Scholarship, 79(3), 1-7. Art. \#2164. https://doi.org/10.4102/koers.v79i3.2164

Verkerk, M. J. (2019). Industrial practices, sustainable development and circular economy: Mitigation of reductionism and silo mentality in the industry. In Vries and Jochemsen.

Open Access This chapter is licensed under the terms of the Creative Commons Attribution 4.0 International License (http://creativecommons.org/licenses/by/4.0/), which permits use, sharing, adaptation, distribution and reproduction in any medium or format, as long as you give appropriate credit to the original author(s) and the source, provide a link to the Creative Commons license and indicate if changes were made.

The images or other third party material in this chapter are included in the chapter's Creative Commons license, unless indicated otherwise in a credit line to the material. If material is not included in the chapter's Creative Commons license and your intended use is not permitted by statutory regulation or exceeds the permitted use, you will need to obtain permission directly from the copyright holder. 